\title{
Emotional and spiritual intelligence, aesthetical and semantic implications
}

\author{
COROIU PETRUTA-MARIA, Professor, $\mathrm{PhD}$ \\ "Transilvania" University Brașov \\ ROMANIA*
}

\begin{abstract}
Musical art is built on its semantics, in the absence of semantics - which is the main reason why a composer writes music, why a singer interprets it, but also the most important reason for the music listener as the receiver - music loses its meaning. Musical compositions can be problematic for interpreters and listeners at various levels of human sensitivity, intelligence and semantic ability, which are all fundamentally connected to conveying and receiving a message transmitted through music. These creations have emotional (psychological) implications, but also more profound ones, spiritual (religious), of which we are more aware and which are emphasized if we take into consideration the concepts of EMOTIONAL INTELLIGENCE and SPIRITUAL INTELLIGENCE.
\end{abstract}

Keywords: spirituality, emotion, aesthetics, semantics, intelligence.

\section{Introduction}

Musical art is built on its semantics, in the absence of semantics - which is the main reason why a composer writes music, why a singer interprets it, but also the most important reason for the music listener as the receiver - music loses its meaning. Musical compositions can be problematic for interpreters and listeners at various levels of human sensitivity, intelligence and semantic ability, which are all fundamentally connected to conveying and receiving a message transmitted through music. These creations have emotional (psychological) implications, but also more profound ones, spiritual (religious), of which we are more aware and which are emphasized if we take into consideration the concepts of EMOTIONAL INTELLIGENCE and SPIRITUAL INTELLIGENCE.

Emotional intelligence (EI) consists in the ability to identify, use and manage one's own emotions (and those of others, as much as possible) in an efficient and empathic way, with a view to obtaining correct answers, achieving major benefits in terms of the quality of the communication and of the human relationships, of thinking and behavior regulation - with multiple consequences deriving from it (improved health, better professional performance, more efficient self-organization).

\footnotetext{
*maniutpetruta@yahoo.com
} 
Emotional and spiritual intelligence are part of the human non-cognitive abilities being - until several decades ago - the only ones truly highlighted in the description of the human personal abilities. This is valid beyond any doubt, because cognitive intelligence is not the only defining trait of a human being (even less so of an artist or of his/her creation).

\section{Emotional and spiritual intelligence - psychologic, aesthetic and semantic connections}

If the beginning of the $20^{\text {th }}$ century saw the emergence of the concept of social intelligence (visible in the moments of collective decision-making), the mid-century saw the emergence of references to individualized emotional factors, which describe the self-regulating capacity. In the 80s, Howard Gardner (Frames of Mind: The Theory of Multiple Intelligences) even introduces the idea of multiple intelligences (interpersonal and intrapersonal). Thus, EQ (Emotional Quotient) refers to the integration of intelligence in emotion, in a given cultural context, and the terminology spread worldwide in the aftermath of Daniel Goleman's book, Emotional Intelligence - Why it can matter more than $I Q$.

The five components of emotional intelligence refer to self-knowledge, self-control, motivation, empathy and mastering social skills. They demonstrate the fact that this emotional quotient (EQ) is different from the intelligence quotient (IQ), which measures human intelligence from the point of view of general mental cognitive abilities, based on standardized tests, built for each age level". The qualities deriving from emotional intelligence offer the person who cultivates it empathy, the ability to find solutions, to express truthfully his/her own opinions, while showing regard for the opinions of others, the ability to overcome negative elements and constructive criticism, to accept their mistakes and to correct them, to improve self-knowledge and self-control.

These are some facts concerning emotional intelligence which help us distinguish it from spiritual intelligence. Spiritual intelligence (SI) was theorized before 2000, and is even more difficult to quantify (measure) than emotional intelligence. Stephen Covey states that: „spiritual intelligence is the central and most fundamental of all the intelligences, because it becomes the source of guidance for the others" (Covey, 2004, p. 53), underlining the true importance of this human personality trait, of which very few of us are aware.

Among its most valuable qualities there are: humility (next to love, the highest virtue, according to the Holy Fathers), respect for others, the ability to move past the immediate, material aspects of existence, the use of virtues and spiritual solutions for mundane problems, the purity and dignity of one's actions, the ability to preserve and cultivate peace in troubled times, stability, the positive approach to difficult situations and personalities, and the vocation to foster your own inner growth and that of the ones around you. Tightly linked 
to the religious element, spiritual intelligence is needed to approach and understand the religious repertory of cult music - which is the focus of this discussion.

If emotional intelligence is the domain of human psychology (and of semantics at the artistic level), spiritual intelligence (SQ) refers to the superior level of human existence which covers the relationship with Divinity, the mental adaptation to transcendence and metaphysics, the problems concerning significance and values, the achievement of a state of inner balance (more than at the psychological level), the religious act (which exceeds by far the strictly moral or expressive act), being attached to hermeneutics. Spiritual intelligence is often defined close to the ideas of "compassion, wisdom, peace" (Wigglesworth, 2006, p. 3), but, if these values remain only at the level of human psychology, of morality, (which may be, to a certain extent, even nonreligious), then they do no reach their final significance.

Similarly, religious music (to which we refer directly here) does not resort only to the semantic skills of its interpreter or of the public, used to decode an expressive message in the sonorous composition, but invokes the deeper substratum of the hermeneutic skills. Hermeneutics involves - in addition to the techniques for analysing strictly theological aspects - the state of prayer, a state which is impossible to theorize completely in a study about music such as this one or even in a study about theology, impossible to exhaust even during a holy existence. It can be supported (if it was instilled in the child during the years spent in the family environment) by religious education, in whose absence - I strongly believe - man will neither be fully prepared for life, for eternity, nor be a very good interpreter or listener of the highest quality music, because the latter implies the state of prayer.

"The purpose of religious education is to lead a useful life, of service to beauty. Religious education reaches the primary and ultimate existential coordinate, that of the ontology of man's craving for the lost state of youth without aging and life without death, for a paradisiac existence" (Nicolescu, 2020 , p. 3). Religious education is included under the term SPIRITUAL (but does not define the same reality) and requires a hermeneutic approach which exceeds the superficial state, that can mask major deficiencies at the level of personality development.

"Spiritual Intelligence is considered by many to be the most important of our many intelligences, and has the power to transform your life, civilization, the planet and the course of history. A truly intelligent person is not one who can simply spout words and numbers; it is someone who can react 'intelligently' to all the opportunities, simulations and problems provided by the environment. Real intelligence means engaging your brain with every aspect of life" (Buzan, 2002, p. XIII). 
Spiritual education also looks beyond the strictly emotional education; both of them are reflected by music and are necessary in order to understand the artistic masterpieces: meta-emotions involve being aware of one's emotions so that they can be expressed more efficiently. If the emotional education stops at data such as: ,learning to manage yourself and your personality effectively, learning to manage your relationships effectively and acceptance of self and others" (Sparrow, Knight, 2006, p. 291), then the musical itinerary to follow has many gaps which have to be filled in order to understand the masterpieces for which it is necessary to acquire these multiple types of intelligence. What else can semantic and hermeneutic analysis be, beyond the strictly technical musical level, than becoming aware and conveying, explaining and shaping these emotions?

Spiritual (religious) education provides full and inner education for the human being, contributing to the ontological fulfilment of man. Anyway, even if religion is not practiced (lived), religious education is part of the so-called general knowledge of any educated person, but ,religious education fails to fully reach its purpose unless it becomes faith, which is the essence of its purpose - the one that provides balance to the human being. The seed of faith is ontologically within man, but it has to (..) bear fruit, to lead to (...) commitment and sacrifice. However, faith cannot be reached only through education" (Nicolescu, 2020, p. 3).

The essential fact is that spiritual education allows access to some of the values which are able to give MEANING to life - the vital element which relates to the unity and value of existence: the Austrian scientist Wolf Singer noticed, before the 2000s, that there is a neural process in the brain which gives unity and meaning, while enhancing the results of cognitive and emotional intelligence.

Values are the highest standards on which we base our multiple choices both in life and in art, and the symbols are the superior reality where meaning exists. Religious music depends directly on the spiritual intelligence of its author, interpreter and audience who has access to it, and decoding and experiencing it from a pragmatic perspective is conditioned by the conscience that the individual acquired in relation to Divinity. This type of research is interdisciplinary, and entails the interaction of various fields, which directly involve aeshetics, semantics and cultural studies: „Studying EI (emotional intelligence) at the interface of brain function, communication and culture requires an interdisciplinary approach that combines the perspectives of neuroscience with those of social psychology, media studies and cultural studies. The aesthetic representation and performance of emotions appeal to all levels of emotional experience in the viewer" (Fahlenbrach, Bartsch, 2008, p. 221).

The examples of religious music culminate the history of the entire musical creation, in any cultural style and space, in any period and socio- 
cultural context. „Christianity exerted a powerful influence on Medieval art (western and byzantine). (...) The Bible inspired the Byzantine psalm music, but especially Bach's Oratorios" (Petrovai, G., 2011), Haydn's The creation and Beethoven's Misa solemnis, J. S. Bach's St. Matthew Passion or compositions such as Crucifixus by Antonio Lotti and its variant in Mandala by Aurel Stroe.

Understanding and internalizing the symbolic value of elements such as the Cross, the sacrifice, the humility - for St. Matthew Passion by J. S. Bach, for example - are essential. These landmarks can easily function as a basic model in understanding them ONLY through a cultivated, deep spiritual intelligence of which we are aware. In its absence, the interpreter, listener or analyst would miss the supreme motive which unleashes the creativity of the authors of these masterpieces: that of expressing, living, conveying to the world the truths of faith (supreme in life, precisely because they are the ones which give meaning).

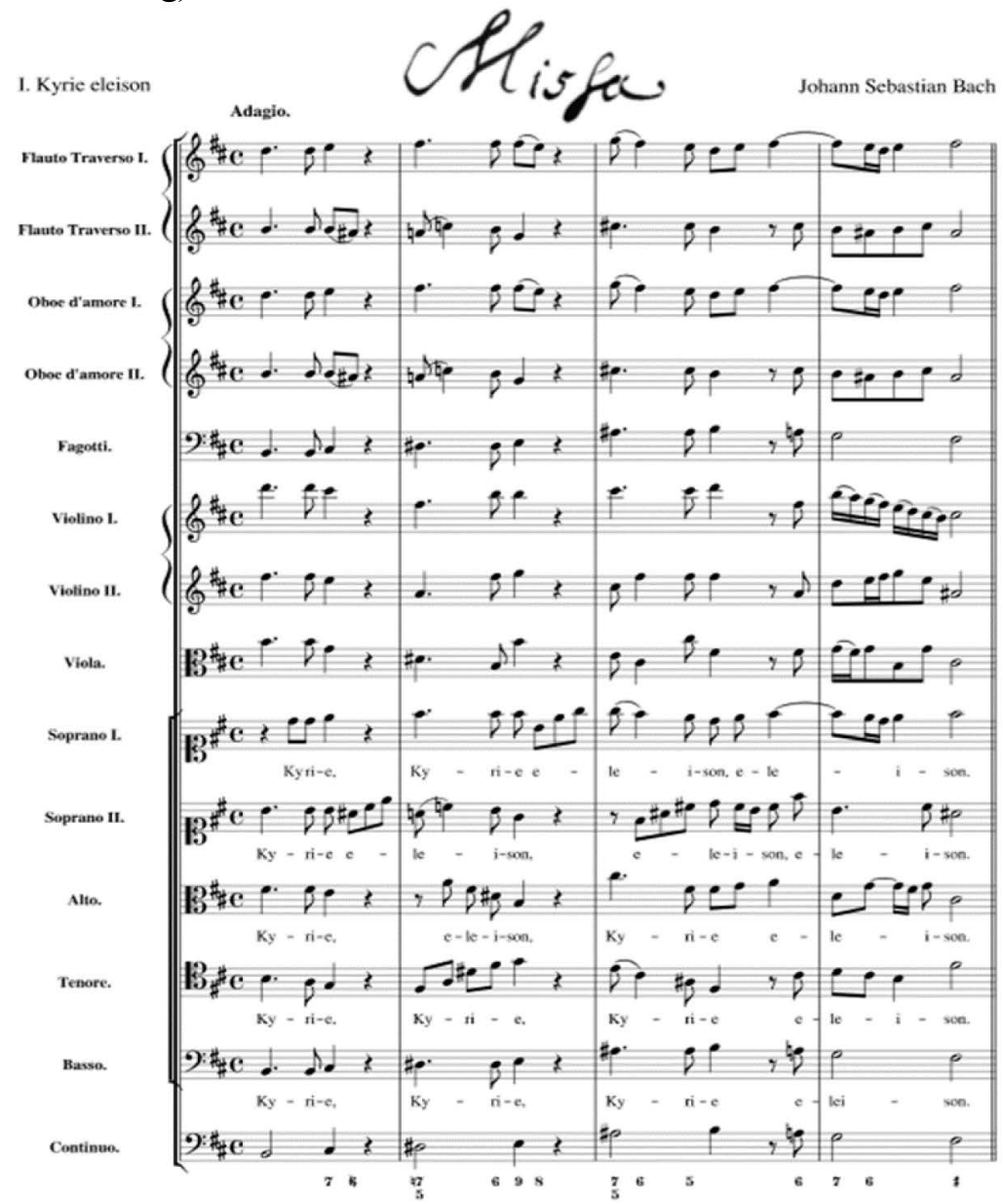

Fig. 1 J. S. Bach, Mass in b minor, Kyrie eleison 
In the absence of the norms of spiritual education, how can we access the profound meanings of the three invocations of divine mercy from the beginning of the Mass in B minor by J. S. Bach, invocations that actually represent the concentrated form of heart prayer in the hesychastic tradition? In the absence of awareness of these unseen, but so real realities, the analysis stops at a strictly musical (possibly informative-theological) framework, but without having the opportunity to enter the depths of the state of prayer that haloes the great Baroque masterpiece.

\section{Conclusions}

Spiritual intelligence is in direct connection and cooperation with all the other forms of intelligence, both in everyday life and in the cultural-artistic environment: „spiritual intelligence progresses naturally from your personal intelligence (knowledge, appreciation and understanding of yourself), through social intelligence (knowledge, appreciation and understanding of other people), to the appreciation and understanding of all other life forms and the universe itself. In fact, contact with, understanding, and an appreciation of nature is a major aspect in the development of your spiritual intelligence" (Buzan, 2002, p. XIX).

At the musical and symbolic level, manipulating the higher emotions and the experiences generated by them represents a must, both for the creative process and for the interpretative one: „the importance of dealing effectively with feelings about differences has never been more urgent than it is at this time in human history. Framing your world through the Emotional Intelligence (...) can be transformational and life changing" (Gardenswartz, Cherbosque, Rowe, 2008, p. 177), even for the artistic phenomenon.

Out of all the values promoted by musical aesthetics, semantics and hermeneutics, beauty (with its external and internal meaning) is the one that confers meaning to the artistic creation: „two components must be part of any religious education: one is beauty, because beauty is essential for life and gives it meaning, it attracts and purifies, and a good relationship with beauty, as Dostoyevsky remarked, can be liberating; the other one is usefulness. Among other things, education is meant to offer attractive aims to our existence and to bring us closer to them, so that after the rough journey of life a person could feel fulfilled and loved" (Nicolescu, 2020). This is why artistic beauty is one of the most important factors of education (formal or continuous, achieved beyond institutions), and music offers the most illuminating examples for this subtle component so important in shaping the human spirit. 


\section{Referințe}

Buzan, T. (2002). The Power of Spiritual Intelligence. HarperCollins Publishers, Inc.

Covey, S. (2004). The 8th Habit: From Effectiveness to Greatness. Simon and Schuster.

Gardenswartz, L., Cherbosque, J., Rowe, A. (2008). Emotional Intelligence for Managing Results in a Diverse World. Mountain View, California: Davies-Black Publishing,

Fahlenbrach, K., Bartsch, A. (2008). Emotional Intelligence at the Interface of Brain Function, Communication, and Culture: The Role of Media Aesthetics in Shaping Empathy, in Scientific Modeling of Emotional Intelligence from a Cultural Perspective (ed. Nicole C. Karafyllis, Gotlind Ulshöferp). Massachusetts Institute of Technology.

Nicolescu, C. (2020). Rostul educației religioase [The purpose of religious education]. Lumina, 14 Sept.

Petrovai, G. (2011). Legătura inseparabilă dintre artă şi religie [The inseparable link between art and religion]. Retrieved from: https://curentul.net/2011/05/03/legaturainseparabila-dintre-arta-si-religie/, May 3/2011.

Sparrow, T., Knight, A. (2006). Applied EI. The Importance of Attitudes in Developing Emotional Intelligence. John Wiley \& Sons Ltd.

Wigglesworth, C. (2006). Why Spiritual Intelligence is Essential to Mature Leadership. Integral Leadership Review, VI, 3. 